\title{
Pelatihan Camtasia Pada Guru SD Panca Budi Untuk Mendukung Transformasi Digital Sekolah Masa Pandemi Covid-19
}

\author{
${ }^{1}$ Sri Wahyuni, ${ }^{2}$ Eko Hariyanto, ${ }^{3}$ Hermansyah, ${ }^{4}$ Saimara Sebayang
}

\author{
${ }^{1}$ Teknik Komputer, Universitas Pembangunan Panca Budi, Medan, \\ ${ }^{2,3}$ Sistem Komputer, Universitas Pembangunan Panca Budi, Medan, \\ ${ }^{4}$ Manajemen, Universitas Pembangunan Panca Budi, Medan \\ email: 'sriwahyuni@dosen.pancabudi.ac.id; '2eko.hariyanto@dosen.pancabudi.ac.id; \\ 3hermansyah@pancabudi.ac.id; ${ }^{4}$ saimarasebayang@dosen.pancabudi.ac.id
}

\begin{abstract}
This PKM program is intended to improve the skills of Elementary School (SD) teachers Panca Budi Medan in carrying out digital transformation of schools. It is conducted by creating interesting animation and E-Learning-based learning materials that can increase students interest in learning in the midst of the Covid-19 pandemic. The teachers of SD Panca Budi Medan are also expected to be examples and share knowledge with other schools and teachers in conducting distance learning, but the material provided is still interesting and increases students, interest in learning even though learning is bold. This PKM in addition to teaching how to use technology in digital transformation, the school also deepens the material for using the Camtasia application to make learning and teaching fun for the students of SD Pendidikan Panca Budi. The target of this PKM is the teachers of SD Panca Budi Medan. At the end of the session, there will also be a test evaluation using the KHoot application where it is hoped that teachers can also apply it online to students. The results obtained are the level of knowledge and skills of teachers in using Camtasia in supporting PJJ during the Covid-19 Pandemic.
\end{abstract}

Keywords. Camtasia, Online, School Digital Transformation

Abstrak. Program PKM ini ditujukan untuk meningkatkan keterampilan guru Sekolah Dasar (SD) Panca Budi Medan dalam melakukan transformasi digital sekolah. Hal ini dilakukan dengan membuat bahan belajar berbasis animasi dan E-Learning yang menarik dan dapat meningkatkan minat belajar para siswa di tengah wabah pandemi Covid-19. Para guru SD Panca Budi Medan juga diharapkan dapat menjadi contoh dan berbagi ilmu kepada sekolah dan guru lain dalam melakukan pembelajaran jarak jauh, namun materi yang diberikan tetap menarik dan meningkatkan minat belajar para siswa walaupun pembelajaran secara daring. PKM ini selain mengajarkan cara penggunaan teknologi dalam transformasi digital Sekolah juga lebih mendalami materi penggunaan aplikasi Camtasia menjadikan suasana belajar dan mengajar menjadi menyenangkan bagi para siswa SD Perguruan Panca Budi. Sasaran dari PKM ini adalah para guru SD Panca Budi Medan. Diakhir sesi juga akan dilakukan evaluasi tes menggunakan aplikais KHoot dimana harapannya para guru juga dapat diterapkan secara online kepada para peserta didik. Hasilnya diperoleh tingkat pengetahuan dan keterangpilan para guru dalam menggunakan Camtasia dalam mendukung PJJ pada masa Pandemi Covid-19.

Kata Kunci. Camtasia, Daring, Transformasi Digital Sekolah

\section{Pendahuluan}

Pandemi Covid-19 yang melanda dunia mengakibatkan perubahan tatanan sistem berskala besar, baik industri, pemerintahan, dan juga pendidikan. Saat ini, semua sangat bergantung kepada koneksi internet atau biasa disebut daring (dalam jaringan)(Guntoro, Lisnawita, \& Sadar, 2019). Penjualan dalam masa pandemic harus menggunakan e-comerce (Wahyuni, Mesra, Lubis, \& Batubara, 2019). Pariwisata juga termasuk aspek yang berdampak (Oroh, Mananeke, 
\& Sangkaeng, 2015), apalagi dunia pendidikan yang tetap harus berjalan walau dalam kondisi pandemi dengan koneksi internet (Sulaa \& Betoambari, 2020). Suksesnya PJJ (Pembelajaran Jarak Jauh) bergantung pada peran guru dan orang tua. Dibutuhkan kerjasama yang baik antara orang tua dan guru (Batubara, Wahyuni, Hariyanto, \& Lubis, 2021) SD Panca Budi merupakan sekolah swasta kategori unggul di Kota Medan, SD Panca Budi adalah sekolah yang memiliki Akreditasi A. SD Panca Budi terletak Jalan Gatot Subroto Km. 4.5 Kelurahan Simpang Tanjung Kecamatan Medan Sunggal, daerah ini merupakan salah satu zona merah pandemi Covid-19 di Sumatera Utara. Kondisi ini, mengakibatkan sekolah tidak diizinkan melakukan pembelajaran tatap muka. SD Panca Budi mengambil kebijakan PJJ. Namun, agar PJJ berjalan sukses para guru diharuskan memiliki kemampuan dalam membuat bahan ajar yang menarik. Aplikasi Camtasia dapat menjadi solusi dari permasalahan yang dihadapi pihak mitra. Kelebihan Aplikasi Camtasia, yaitu mudah digunakan oleh para guru yang masih tergolong pemula dalam membuat video pembelajaran berbasis multimedia. Dalam menghadapi masa pandemi, semua lapisan masyarakat dituntut belajar menggunakan internet yang sehat dan aman (Hariyanto; 2020). Dalam menunjang SDM yang unggul dibutuhkan pelatihan dan edukasi yang terencana dan dengan output peningkatan kuliatas dan mutu (Sebayang, Nuzuliati, \& Wahyuni, 2021). Pengembangan bahan ajar dengan berbagai model juga harus dapat dikusai oleh para guru, sehingga kualitas kurikulum yang diajarkan dapat meningkatkan prestasi para siswa (Pasaribu, Ritonga, Watrianthos, \& Hidayah, 2020). Pengembangan evaluasi bahan ajar juga sangat dibutuhkan dalam kesusksesan peningkatan mutu kurikulum (Fitriyani \& Dwi, 2021). Suksesnya SDM (Sumber Daya Manusia) yang unggul bukan hanya melalui pelatihan, namun juga dibarengi dengan pendampingan secara langsung dan berkala serta harus dapat dimonitoring dan dievaluasi (Mesra, Wahyuni, Sari, \& Pane, 2021). Peningkatan kualitas SDM juga harus melibatkan peran instansi pemerintah (Prasetyo, 2017). Pembelajaran yang menarik dapat meningkatkan prestasi belajar para peserta didik terutama tingkat sekolah dasar (hermansyah, 2021). Pada masa pandemi, literasi digital juga sangat dibutuhkan agar SDM para guru SD Panca Budi mengalami peningkatan kapasitas dalam mengajar walaupun harus melakukan aktifitas di dalam rumah atau dengan pembatasan (Somantri \& Sari, 2021). Optimalisasi digital sekolah dalam masa pandemi covid-19 sangat bergantung pada koneksi internet, banyak perguruan tinggi sudah melakukan pelatihan kepada para guru agar dapat melaksanakan pembelajaran daring secara optimal dan maksimal (Fitriyani \& Dwi, 2021). Salah satu aplikasi yang dapat digunakan sebagai pendukung dalam menjalankan digitalisasi sekolah dalam masa pandemi covid19, yatiu Aplikasi Camtasia. Aplikasi ini adalah salah satu aplikasi yang dapat dijadikan tools dalam membuat video pembelajaran untuk dapat mendukung pembelajaran yang menyenangkan bagi peserta didik, sehingga walaupun pembelajaran dilakukan secara daring para guru dapat dengan mudah menyampaikan materi pembelajaran dengan baik dan menarik (Ar, Awaludin, Hartuti, \& Rahadyan, 2019). Aplikasi Camtasia dapat dijadikan sebagai solusi dalam menyelesaikan permasalahan yang dihadapi pihak SD Panca Budi khusunya para guru, kemudian aplikasi Camtasia juga dapat mudah digunakan oleh para guru pemula dengan pembuatan media pembelajaran. Berikut permasalahan yang dihadapi Sekolah Dasar Panca Budi dalam melakukan transformasi digital sekolah yang perlu diperhatikan:

a. Kurangnya pengetahuan dan keterampilan dalam membuat 
bahan ajar berbasis animasi.

b. Melaksanakan evaluasi belajar kepada para siswa dengan metode evaluasi belajar manual, yaitu tes dalam bentuk esai. Kurangnya menggunakan aplikasi evaluasi belajar yang dapat meningkatkan minat belajar dan motivasi belajar para peserta didik.

c. Kurangnya kemampuan dalam menggunakan aplikasi Camtasia.

PKM pelatihan Camtasia pada guru SD Panca Budi dilakukan dengan tujuan meningkatkan keterampilan para guru SD Panca Budi menggunakan aplikasi Camtasia dalam membuat bahan ajar berbasis multimedia.

\section{Metode Ilmiah}

Tim Pengabdian Kepada Masyarakat (PKM) mengawali semua kegiatan dengan audiensi kepada kepala sekolah SD panca Budi, kemudian melakukan penandatanganan berita cara bersedia menjadi mitra PKM. Dalam menentukan solusi bagi permasalahan yang dihadapi mitra, tim PKM melakukan diskusi kepada mitra yaitu tim Kurikulum dan manajemen SD Panca Budi dalam menentukan metode yang sesuai pada

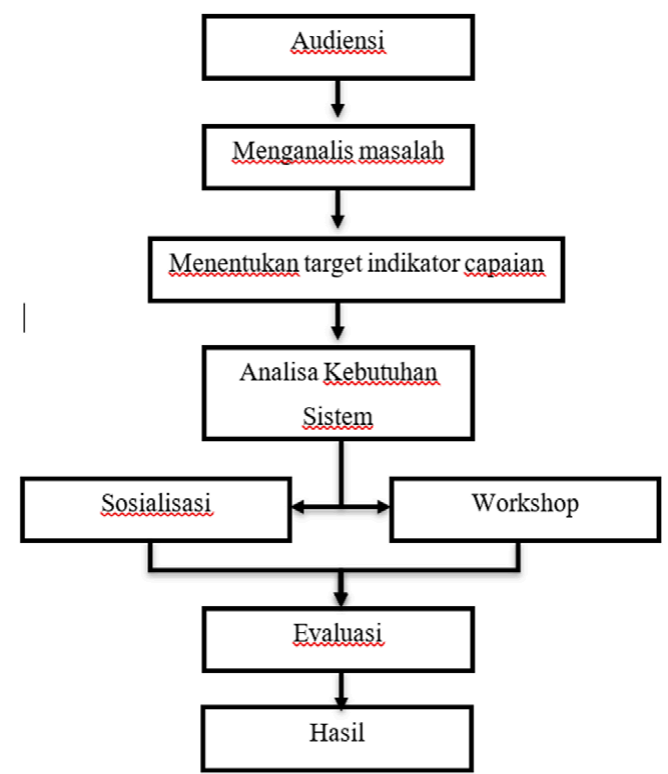

Gambar 1. Metode Pengabdian pelaksanaan program PKM. Tim juga diberikan kesempatan dan kemudahan dari mitra dalam memanfaatkan lokasi ruang kantor SD Panca Budi Medan dalam melakukan kegiatan PKM. Pelaksanaan tim tetap mematuhi protokol kesehatan dan dalam menunjang kegiatan program melibatkan para mahasiswa Universitas Pembangunan Panca Budi Medan program studi Teknik Komputer. Metode PKM yang dilaksanakan Tim ditunjukan oleh Gambar 1.

\section{Metode Pendekatan}

Tim PKM menawarkan pendekatan metode, yaitu:

\section{a. Ceramah dan Diskusi}

Kegiatan diawali dengan sesi ceramah dan sesi berikutnya tanya jawab diskusi. Peserta pelatihan terdiri dari guru SD Panca Budi terutama para wali kelas, serta didampingi kepala sekolah, tim manajemen SD Panca Budi yang bertanggung jawab pada peningkatan kualitas kurikulum. Dalam memudahkan sharing ilmu sebelum pelaksanaan program kegiatan bahan materi telah diberikan kepada para peserta. Peserta pelatihan terdiri dari 30 peserta yang terdiri dari guru wali kelas dan guru bidang studi SD Panca Budi. Adapun rincian materi yang di berikan pada saat pelatihan yaitu sebagi berikut:

- Materi Manajemen SDM sekolah dalam menggunakan Teknologi Informasi untuk mendukung pembuatan bahan pembelajaran yang menarik minat belajar dan berkualitas pada masa pandemi Covid-19, sehingga transformasi digital sekolah dapat berlangsung dengaan lancar. Pandemi Covid-19 merupakan alasan banyak SDM harus meningkatkan pengetahuan, keterampilan, dan skill dalam bidang teknologi. Karena suka atau tidak suka, mau atau tidak mau setiap individu dunia pendidikan di paksa harus menggunakan 
teknologi terutama internet dalam mendukung pembelajaran jarak jauh. Materi tentang manajemen SDM dalam menghadapi masa pandemi covid-19 disampaikan oleh bapak Saimara Sebayang SE., M.Si anggota tim PKM.

- Pengantar tentang aplikasi yang dapat digunakan dalam membuat bahan ajar menarik dan mudah di pahami oleh para guru SD Panca Budi Medan. Tema materi meliputi pengantar, pengenalan aplikasi Camtasia, cara mendownload aplikasi Camtasia, dan cara menginstal aplikasi camtasia oleh Sri Wahyuni, S.Kom., M.Kom.

b. Ceramah dan Diskusi

Praktik secara langsung membuat bahan ajar menarik dan mudah dipahami dengan aplikasi Camtasia pada peserta pelatihan yang dipaparkan oleh salah satu tim PKM, yaitu bapak Eko Hariyanto, S.Kom., M.Kom dan Hermansyah, S.Kom., M.Kom. Mekanisme praktik secara langsung, dimana para narasumber langsung membuat bahan ajar yang ditampilkan menggunakan infokus, kemudian para peserta secara langsung mengikuti praktik langkah demi langkah menggunakan laptop pribadi. Jika ada peserta yang tertinggal, kurang jelas, dan mengalami kendala teknis pada pelaksanaan workshop, maka akan di pandu langsung oleh para mahasiswa Program Studi Teknik Komputer dan sistem komputer Universitas Pembangunan Panca Budi Medan yang memantau dan segera membantu pelaksanan program PKM. Semua pelaksanaan workshop juga disiapkan tim semenarik mungkin, sehingga dapat diterapkan pada saat pembelajaran kepada para siswa, seperti pelaksanaan evaluasi menggunakan aplikasi Kahoot, dengan harapan para guru juga dapat menggunakan aplikasi tersebut dalam melaksanakan evaluasi kepada para siswa ajar.

\section{Prosedur Kerja}

Kegiatan PKM ini diawali dengan pendekatan kepada pihak SD (Sekolah Dasar) Panca Budi yang dilakukan melalui sosisalisasi, baik kepala sekolah sebagai pengambil kebijakan dan keputusan, maupun kepada para guru secara langsung merupakan peserta dalam acara pelatihan ini nantinya. Rangkaian pelaksanaan program berikutnya, yaitu workshop pengenalan teknologi dalam transformasi digital sekolah dalam masa pandemi covid-19 serta peran teknologi.

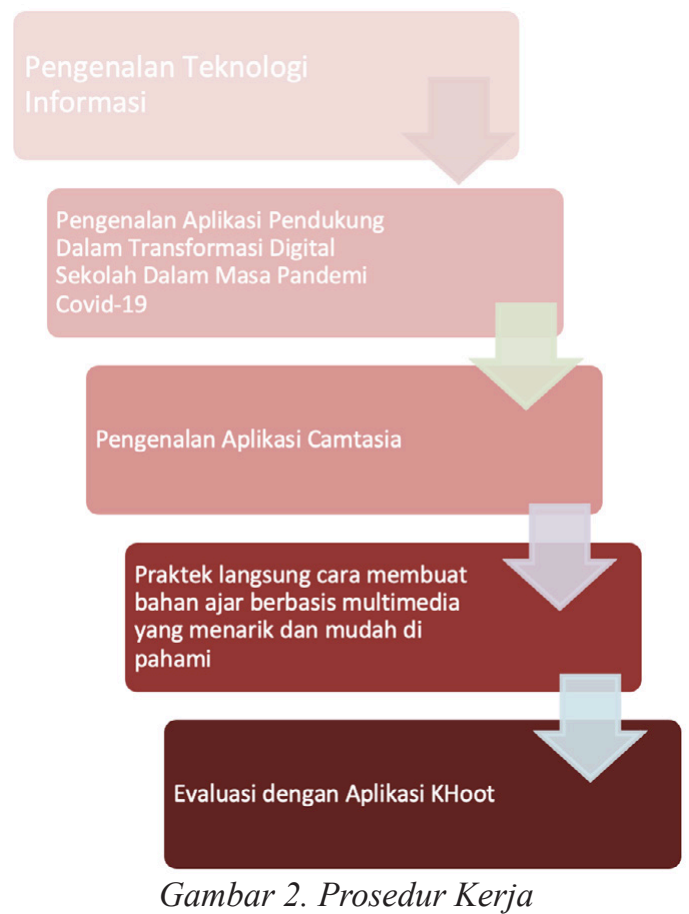

Selanjutnya, dilakukan diskusi dan tanya jawab. Sesi akhir kegiatan, melaksanakan praktik langsung penggunaan apikasi Camtasia dalam membuat media pembelajaran yang sesuai dengan masa pandemi covid-19. Agar program pengabdian kepada masyarakat ini terus berlanjut akan diadakan pendampingan terhadap SD Panca Budi. Pendampingan akan dilakukan oleh tim pelaksana melalui media grup diskusi telegram, dimana para guru akan bertanya langsung, kemudian tim akan memberikan jawaban solusi secara langsung jika pihak SD Panca Budi mengalami kendala dalam membuat 
bahan ajar dengan aplikasi Camtasia. Adapun realisasi program PKM pelatihan Camtasia pada guru SD Panca Budi untuk mendukung transformasi digital sekolah masa pandemi covid-19 pada Gambar 2.

\section{Hasil dan Pembahasan}

\section{Hasil}

Mitra, yaitu pihak SD Panca Budi sangat mengapresiasi program PKM yang dilakukan tim dan mengharapkan program PKM yang berkelanjutan. Adapun hasil dari program PKM yang dilaksanakan pada SD Panca Budi adalah sebagai berikut :

a. Terjadi peningkatan wawasan tentang teknologi informasi dan pemahaman pentingnya peran IT dalam melaksanakan PJJ. Ini dapat dibuktikan dengan evaluasi prates dan postes dengan aplikasi Kahoot, dimana terdapat peningkatan score yang diperoleh pada saat posttest workshop dibandingkan dengan pretest sebelum workshop.

b. Kemampuan membuat bahan ajar yang berbasis multimedia dengan aplikasi Camtasia.

c. Kemampuan mengunggah atau upload hasil video pembelajaran yang telah di buat dengan aplikasi Camtasia di yuotube.

d. Peningkatan wawasan dalam menggunakan aplikasi yang menarik saat melaksanakan evaluasi pembelajaran, sehingga dapat meningkatkan minat belajar para siswa yang berakibat pada peningkatan prestasi siswa, walaupun dalam masa pandemi covid -19 .

e. Pendampingan keberlanjutan program melalui grup telegram sehingga para peserta dapat terus di monitoring oleh tim.

\section{Pembahasan}

Adapun beberapa pembahasan yang menjadi fokus dari program
PKM diharapkan dapat meningkatkan keberlanjutan program sebagai berikut:

\section{a. Peserta Kegiatan PKM}

Workshop Optimalisasi Camtasia dalam tranformasi digital Sekolah melalui PJJ pada masa pandemi covid-19 di SD Panca Budi untuk membuat bahan ajar yang menarik sehingga meningkatkan minat belajar para siswa dilakukan dengan standar dan protokol Covid-19, terlebih dahulu mencuci tangan, menjaga jarak, dan menggunakan masker dan faceself. Sasaran dari kegiatan PKM ini adalah para perangkat SD Panca Budi, khususnya para guru dan para wali kelas. Acara dibuka oleh kata sambutan dari Kepala Sekolah, Bapak Ronny Irwanto, S.S. yang sangat mengapresiasi dan menyambut baik kegiatan PKM ini.

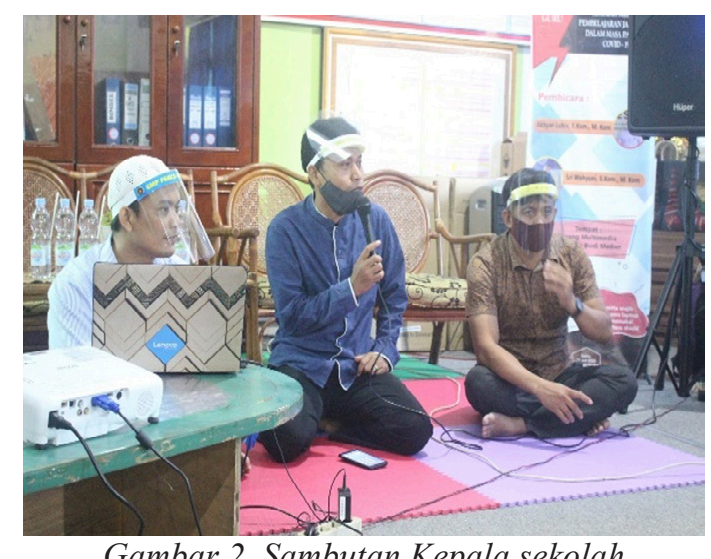

Gambar 2. Sambutan Kepala sekolah

Dalam melakukan pelatihan secara langsung tim mengalami kendala, yaitu masih terdapat perangkat laptop para guru yang tidak sesuai dengan spesifikasi kebutuhan dalam menggunakan aplikasi Camtasia, sehingga mengalami berbagai kendala dan waktu pelatihan menjadi lebih lama dari perkiraan estimasi awal karena masih harus melakukan setting dan pengaturan pada laptop para guru. Peserta terdiri dari 30 orang yang dapat ditunjukan dari berita acara dan absen para peserta yang terdapat dalam lampiran. Tim PKM melakukan evaluais dengan melakukan tes menggunakan aplikasi Kahoot. 


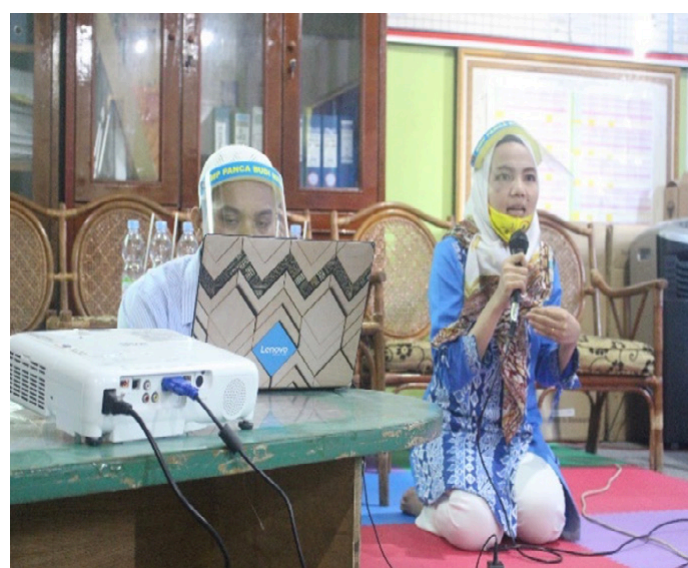

Gambar 3. Pemaparan materi oleh tim

Dalam melakukan pelatihan secara langsung tim mengalami kendala, yaitu masih terdapat perangkat laptop para guru yang tidak sesuai dengan spesifikasi kebutuhan dalam menggunakan aplikasi Camtasia, sehingga mengalami berbagai kendala dan waktu pelatihan menjadi lebih lama dari perkiraan estimasi awal karena masih harus melakukan setting dan pengaturan pada laptop para guru. Peserta terdiri dari 30 orang yang dapat ditunjukan dari berita acara dan absen para peserta yang terdapat dalam lampiran. Tim PKM melakukan evaluais dengan melakukan tes menggunakan aplikasi Kahoot.

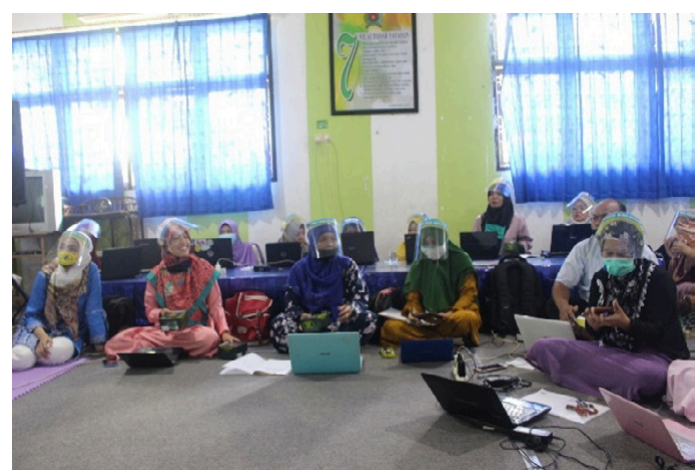

Gambar 4. Perserta PKM

\section{b. Persiapan materi}

Sebelum memberikan materi tim PKM telah melakukan sosialisasi dan berdiskusi dengan kepala sekolah dan wakil kepala sekolah bidang akademik dan kurikulum tentang kebutuhan materi dan permasalahan yang di hadapi SD Panca Budi. Tim juga melaksanakan diskusi internal antara tim dengan tim kurikulum SD Panca Budi dalam membuat bahan materi untuk di bagikan sebelum pelaksanaan program dilakukan sehingga para peserta lebih menguasai materi pada saat workshop. Adapun materi yang diberikan kepada peserta di SD Panca Budi, yaitu diantaranya :

- Pentingnya peran dan penerapan teknologi informasi khususnya internet dalam transformasi digital sekolah pada masa pandemi Covid-19.

- Pengenalan Aplikasi Camtasia. Aplikasi Camtasia merupakan aplikasi yang masih tergolong asing bagi para guru SD Panca Budi. Dibutuhkan proses pengenalan aplikasi baik secara teori tentang keunggulan dan kelemahan aplikasi, juga secara praktik, yaitu langsung mendownload aplikasi dan menginstal aplikasi Camtasia.

- Cara membuat bahan ajar berbasis animasi dan E-Learning yang menarik dan mudah di pahami para siswa, sehingga dapat meningkatkan minat belajar para siswa dengan aplikasi Camtasia.

- Evaluasi diakhir sesi dengan tes menggunakan aplikasi Kahoot secara online.

- $\quad$ Praktik Secara Langsung.

Para peserta pelatihan membuat bahan ajar didampingi langsung oleh tim, sehingga jika terdapat kendala baik software maupun hardware tim langsung dapat mengatasi masalah tersebut.

c. Keterlibatan Mahasiswa

Dalam menciptakan suasana akademik dilingkungan Univeritas Pembangunan Panca Budi, salah satunya hubungan antara mahasiswa dan dosen, menunjang kegiatan kampus merdeka belajar, serta aktivitas antara mahasiswa dan dosen di luar akademik. Disamping dari keharusan melibatkan beberapa mahasiswa dalam PKM, secara personal 
bagi mahasiwa keterlibatan mereka dalam program PKM dapat menambah wawasan, pengetahuan, dan keterampilan mahasiswa dalam dunia kerja dan masyarakat. Berikut merupakan namanama mahasiswa yang berperan dalam kegiatan PKM ini.

- $\quad$ Anugrah Putra

Salah satu mahasiswa program studi teknik komputer semester 5. Pada Program PKM ini memiliki tugas membagikan undangan dan materi hardcopy kepada para peserta workshop PKM. Selain itu, pada saat pelaksanan mendampingi dan mengajarkan para peserta pelatihan yang mengalami ketertinggalan pada saat kegiatan workshop dibantu juga.

- Manja Darwiyah

Melaksanakan tugas dokumentasi kegitan PKM dan membuat video luaran dari Pelaksanaan PKM. Sembari melakukan pendampingan kepada para peserta pelatihan.

\section{d. Jenis Kepakaran}

Program PKM dapat berjalan lancar dan sukses karena melibatkan multi disiplin ilmu, bukan hanya bidang komputer, namun juga melibatkan dosen lain sesuai dengan kebutuhan kepakaran dalam menyelesaiakan permasalahan yang dihadapi mitra, yaitu SD Panca Budi. Tim terdiri dari 4 orang dosen, masingmasing memiliki kepakaran bidangnya sendiri. Adapun jenis kepakaran yang diperlukan dalam PKM ini ditunjukan pada Tabel 1.

\section{e. Kendala}

Adapun kendala yang dihadapi pada saat pelatihan, yaitu sebagian kecil para peserta memiliki perangkat atau spesifikasi laptop yang kurang memadai, sehingga pada saat pelatihan tim harus meluangkan waktu dalam melakukan cek perangkat. Rencana kerja yang sudah di tentukan pada saat proposal PKM mengalami sedikit perubahan terutama durasi PKM lebih lama dari waktu awal ditentukan pada saat proposal PKM di buat. Namun, kehadiran para mahasiswa program studi Teknik komputer Universitas Pembangunan Panca Budi hal ini dapat meminimalkan kendala, sehingga pelaksanaan program PKM mengalami kelancaran walaupun menambah durasi pelaksanaan PKM. Pelaksanan program PKM sangat bergantung pada koneksi internet yang stabil. Agar pembelajaran berjalan lancar terutama pada pelaksaan workshop saat mengupload video pembelajaran yang dibuat ke dalam youtube. Namun, koneksi internet pada saat pelaksanaan kurang stabil sehingga masih terdapat kendala koneksi jaringan internet. Kedapannya diharapkan bantuan pemerintah seperti memberikan bantuan upgrade perangkat para guru dan bantuan koneksi internet untuk para guru dan siswa sebagai peserta didik.

Tabel 1. Jenis Kepakaran

\begin{tabular}{cccl}
\hline No & \multicolumn{1}{c}{ Nama Dosen } & $\begin{array}{c}\text { Jenis } \\
\text { Kepakaran }\end{array}$ & \multicolumn{1}{c}{ Penyelesaian Masalah } \\
\hline 1 & Sri Wahyuni, S.Kom.,M.Kom & $\begin{array}{l}\text { Information } \\
\text { Technology }\end{array}$ & $\begin{array}{l}\text { Penerapan teknologi informasi yang digunakan dalam } \\
\text { membuat bahan ajar yang menarik }\end{array}$ \\
\hline 2 & Eko Hariyanto, S.Kom.,M.Kom & $\begin{array}{l}\text { Sistem } \\
\text { Informasi }\end{array}$ & $\begin{array}{l}\text { Implementasi internet dalam mendukung PJJ masa } \\
\text { Pandemi Covid-19 }\end{array}$ \\
\hline 3 & Hermansyah, S.Kom.,M.Kom & Multimedia & $\begin{array}{l}\text { Memberikan secara langsung workshop Pelatihan dalam } \\
\text { membuat bahan ajar yang menarik dengan aplikasi } \\
\text { Camtasia }\end{array}$ \\
\hline 4 & Saimara Sebayang, Se.,M.Si & $\begin{array}{l}\text { Manajemen } \\
\text { SDM }\end{array}$ & $\begin{array}{l}\text { Melakukan pelatihan yang berhubungan dengan } \\
\text { manajemen kelas dan suasana akademik terutama } \\
\text { manajemen SDM para guru }\end{array}$ \\
\hline
\end{tabular}




\section{Kesimpulan dan Saran}

\section{Kesimpulan}

Setelah menyelesaikan pengabdian masyarakat ini, tim melakukan analisis serta menarik kesimpulan, yaitu:

a. Workshop yang dilaksanakan berjalan lancar. Target indikator yang ditentukan diawal program tercapai $85 \%$ (delapan puluh lima persen) dari $100 \%$ (seratus persen) target yang telah di tentukan. Hal ini dibuktikan dengan para peserta didik dapat membuat bahan ajar berbasis multimedia dengan aplikasi Camtasia dan hasil evaluasi dengan aplikasi Kahoot.

b. Program PKM berjalan sukses, hal tersebut tidak terlepas dari peran serta mitra yang sangat membantu dalam pelaksanaan program, yaitu kepala sekolah SD Panca Budi, wakil kepala sekolah, dan para guru sebagai peserta pelatihan.

c. Optimalisasi Camtasia dalam Tranformasi Digital Sekolah PJJ pada pandemi Covid-19 di SD Panca Budi sangat dibutuhkan para guru dalam menyiapkan pembelajaran secara online terlihat dari pra tes dan pasca tes yang dilakukan oleh tim PKM, menunjukan peningkatan wawasan dan pengetahuan para guru dalam membuat materi pembelajaran yang berkualitas sehingga meningkatkan prestasi para siswa.

\section{Saran}

Berikut saran untuk pengembangan lanjutan pada kegiatan PKM pelatihan Optimalisasi Camtasia di SD Panca Budi, yaitu:

a. Diharapkan dilakukan pelatihan lebih lanjut dan berkelanjutan dengan aplikasi video pembelajaran lainnya agar wawasan dan keterampilan para guru lebih meningkat.

b. Dengan program pelatihan yang telah diberikan harapanya para guru dapat menerapkan ilmu yang diperoleh dalam pengajaran seharihari dan pihak sekolah melakukan monitoring dan evaluasi agar proses pembelajaran secara daring menjadi berkualitas.

c. PJJ pada masa pandemi covid-19 sangat bergantung pada koneksi internet dan perangkat hardware, yaitu spesifikasi laptop yang bagus, maka dari itu dibutuhkan perhatian pemerintah dalam memberikan bantuan kepada para guru ataupun para siswa agar PJJ dapat berjalan lancar. Mengingat kebutuhan perangkat dan koneksi internet yang baik dari kedua pihak baik guru maupun peserta didik.

d. Dalam menunjang kesuksesan PJJ, khusunya untuk tingkat sekolah dasar sangat dibutuhkan kerjasama antara pihak sekolah, yaitu para guru dan orang tua yang harus melakukan monitoring dan pendampingan pada saat proses pembelajaran PJJ dirumah.

\section{Ucapan Terimakasih}

a. Terimakasih kepada Lembaga Penelitian dan Pengabdaian Masyarakat (LPPM) Universitas Pembangunan Panca Budi yang telah memberikan dukungan sehingga PKM ini dapat berjalan dengan lancar.

b. Terimkasih kepada Kepala Sekolah Dasar Panca Budi Bapak Ronny Irwanto, S.S. dan seluruh staf pegawai, serta para guru yang telah bekerja sama sebagai mitra, sehingga terwujudnya program PKM yang berjalan lancar dan sukses.

\section{DAFTAR PUSTAKA}

Ar, A., Awaludin, R., Hartuti, P. M., \& Rahadyan, A. (2019). Aplikasi 
Cabri 3D Berbantu Camtasia Studio untuk Pembelajaran Matematika di SMP. 10(1), 68-75.

Batubara, S., Wahyuni, S., Hariyanto, E., \& Lubis, A. (2021). Webinar Menangkal Cyberporn Pada Internet dan Android Memanfaatan Add Ons dan Aplikasi Antipornografi Parental Control Di SMA Panca Budi. Jurnal Abdimas BSI: Jurnal Pengabdian Kepada Masyarakat, 4(1), 164-173. https://doi.org/10.31294/jabdimas. v4i1.9048

Fitriyani, H., \& Dwi, A. (2021). Pelatihan Pengembangan Instrumen Evaluasi Online Menggunakan Google Form Bagi Guru Sekolah Dasar Madrasah Ibtidaiyah. Jurnal Ethos, 9(2), 204-215.

Guntoro, G., Lisnawita, L., \& Sadar, M. (2019). Pelatihan Internet Sehat dan Aman bagi Siswa SMK Masmur Pekanbaru. Jurnal Pengabdian Pada Masyarakat, 4(2), 223-230. https:// doi.org/10.30653/002.201942.105

hermansyah. (2021). Perancangan Aplikasi Pembelajaran Interaktif Pengenalan Unsur Kimia dengan Metode Computer Based Instruction ( CBI ). 9(3), 74-78.

Mesra, B., Wahyuni, S., Sari, M. M., \& Pane, D. N. (2021). E-Commerce Sebagai Media Pemasaran Produk Industri Rumah Tangga Di Desa Klambir Lima Kebun. 1(3), 115120.

Oroh, S., Mananeke, L., \& Sangkaeng, S. (2015). Pengaruh Citra, Promosi Dan Kualitas Pelayanan Objek Wisata Terhadap Kepuasan Wisatawan Di Objek Wisata Taman Laut Bunaken Sulawesi Utara. Jurnal Riset Ekonomi, Manajemen, Bisnis Dan Akuntansi, 3(3), 10891100.

Pasaribu, E. Z., Ritonga, M. W., Watrianthos, R., \& Hidayah, M. (2020). Pengembangan Lembar Kerja Siswa Matematika Berbasis
Model Discovery Learning Terhadap Kemampuan Pemahaman Konsep Matematis Siswa Kelas Xi Di Sma Negeri 1 Rantau Selatan. Maju, 7(2), 212-220.

Prasetyo, R. A. (2017). "Peranan Bumdes Dalam Pembangunan Dan Pemberdayaan Masyarakat Di Desa Pejambon Kecamatan ... Jurnal Dialektika Volume, XI(March 2016), 86-100.

Sebayang, S., Nuzuliati, \& Wahyuni, S. (2021). Edukasi Kepada Perangkat Desa Tentang Motivasi Kerja Kepemimpinan dan Budaya Organisasi. 1(1), 51-58.

Somantri, O., \& Sari, Y. P. (2021). Workshop Literasi Digital Menggunakan Reference Manager Pada Masa Pandemi COVID-19. Ethos: Jurnal Penelitian Dan Pengabdian Kepada Masyarakat, 9(2), 228-236.

Sulaa, D. I. K., \& Betoambari, K. (2020). PELATIHAN CITIZEN JOURNALISM BAGI REMAJA USIA SEKOLAH DI WILYAH PESISIR PANTAI NIRWANA. 20-27.

Wahyuni, S., Mesra, B., Lubis, A., \& Batubara, S. (2019). Penjualan Online Ikan Asin Sebagai Salah Satu Usaha Meningkatkan Pendapatan Masyarakat Nelayan Bagan Deli. Ethos: Jurnal Penelitian Dan Pengabdian Kepada Masyarakat, 8(1), 89-94. 